\title{
Women's mammography experience and its impact on screening adherence
}

\author{
Tricia S. Tang ${ }^{\prime *}$, Stephanie K. Patterson ${ }^{2}$, Marilyn A. Roubidoux ${ }^{2}$ and Linping Duan ${ }^{3}$ \\ 'Department of Medical Education, University of Michigan Medical School, Ann Arbor, MI, USA \\ ${ }^{2}$ Department of Radiology, University of Michigan Health System, Ann Arbor, MI, USA \\ ${ }^{3}$ Department of Psychiatry, University of Michigan Health System, Ann Arbor, MI, USA
}

* Correspondence to: Department of Medical Education, University of Michigan Medical School, GII09 Towsley Center, SPC 5201 Ann Arbor. Ml 481095201, USA.

E-mail: tangts@umich.edu
Received: 22 April 2008

Revised: 19 August 2008

Accepted: 27 August 2008

\begin{abstract}
Objectives: Although rates for first-time and recent mammography screening have increased for women in the US in the past decade, rates for repeat mammography remain low. This study aimed to conduct an analysis of women's mammography experience, to examine the rates of repeat mammography and to identify the significant predictors of repeat mammography within 12 and 18 months of the index mammogram.

Methods: Participants were 397 women obtaining a screening mammogram (i.e. index) at three university-affiliated radiology clinics. Following the index mammogram, women completed the measures assessing demographic background, health history, breast cancer knowledge, risk, and screening history, and aspects of the mammography experience. Eighteen months following the index mammogram, 296 women were contacted via telephone to assess repeat mammography behavior.

Results: Factor analysis of a mammography experience survey yielded four major components including satisfaction with clinic services, physical experience, psychological experience, and communication with clinic staff. Twelve-month and 18-month repeat mammography rates were 37 and $68 \%$, respectively. Logistic regression models found lifetime number of mammograms to predict repeat mammography at 12 and 18 months. In addition, the number of clinical breast exams obtained in the past 5 years predicted repeat mammography at 12 months, while having scheduled a mammography appointment predicted repeat mammography at 18 months.

Conclusions: Based on these findings, strategies to increase mammography adherence include implementing a formal reminder system that prompts patients (e.g. postcard, automated telephone call) to schedule an annual mammogram or training clinic staff to automatically schedule an annual mammogram at the time of the current screening appointment.

Copyright (C) 2008 John Wiley \& Sons, Ltd.
\end{abstract}

Keywords: cancer; oncology; repeat mammography; screening adherence; mammography experience

\section{Introduction}

Breast cancer is the most frequently diagnosed cancer and second leading cause of cancer death among women in Michigan and the United States overall $[1,2]$. Routine mammography can reduce breast cancer mortality by $40-45 \%$ among women between the ages of 40 and $69[3,4]$. The efficacy of mammography in breast cancer detection and mortality reduction is contingent upon repeat mammography behavior (i.e. adherence to screening guidelines) [5]. The American Cancer Society screening guidelines recommend women to obtain a baseline mammogram at age 40 and for women 40 and older to obtain annual mammograms [6].

Mammography screening behavior has been investigated at three endpoints: ever screened, recently screened, and consecutive on-schedule screening (i.e. repeat mammography). Although rates for first-time and recent mammography screening have increased for women in the US in the past decade, [7-9] screening rates for repeat mammography remain low. In this study, we have defined 'repeat mammography' as having two consecutive mammograms within a 12-month or 18-month interval. Recent studies of repeat mammography using the 18-month definition have reported rates from 61 to $76 \%$ [10-13]. A meta-analysis of 11 studies (1995-2001) targeting women 50 and older found the weighted average percentage of repeat mammography (using screening intervals from 12 to 24 months) across all studies to be $53 \%$ [14]. Clearly, screening age women, on the whole, are not practicing sustained mammography adherence. 
Research, to date, has found a number of demographic and health/medical background variables significantly associated with repeat mammography behavior, including younger age, higher education, higher income, being Caucasian, being married, recent pap smear, physician recommendation, prior breast problems, prior breast biopsy, family history of breast cancer [15-18]. While these variables are important, other factors including the role of women's mammography experience may also be related to repeat mammography behavior.

Research on repeat mammography behavior among women in the US, has found pain, anxiety, and satisfaction with clinic service and health-care providers as important factors in the mammography experience. Several studies have found women to endorse some degree of pain while undergoing mammography [19-23]. However, the extent to which pain deters women from practicing repeat mammography has not been well examined. In addition to physical discomfort, psychological distress such as anxiety or embarrassment has been found to be associated with repeat mammography behavior [24-26]. Finally, satisfaction with clinic service and/or health-care providers has been shown to influence women's decision to have repeat mammography [26,27]. Women more satisfied with their patient-provider relationship (e.g. communication, rapport, respect) were more likely to return for annual mammography [27]. Physical discomfort, psychological distress, and satisfaction with service and providers have been independently reported or found to be the factors in repeat mammography behavior among women in the US, but seldom have they been examined collectively or in consideration with other demographic and health/medical predictors of screening. This area warrants further investigation.

The objectives of this study were to conduct an analysis of women's mammography experience, to determine the rates of repeat mammography at 12 and 18 months, and to identify the best predictors of repeat mammography. We hypothesize that the aspects of the mammography experience will be the strongest predictors of repeat screening.

\section{Methods}

\section{Participants and procedures}

The present study followed a cross-sectional, longitudinal design recruiting 397 consecutive women obtaining a screening mammogram at three radiology clinics affiliated with the University of Michigan Health System. This study was approved by the Institutional Review Board of University of Michigan. To be eligible to participate in the study, women had to be 40 years or older, obtaining a mammogram for screening purposes, and literate in the English language (the questionnaire was only offered in English). The screening mammogram obtained at the outset of the study was designated as the 'index mammogram'. The 'repeat mammogram' was the screening mammogram women were expected to obtain within 12 or 18 months of their index mammogram.

Flyers announcing the study were placed at the reception desk of each screening site. The flyers informed the patients that a study on women's mammography experience was being conducted at the screening clinic and a research assistant would be inviting each woman to participate in the study. Women who did not want to be approached were asked to inform the clinic receptionist. The clinic receptionist flagged charts of patients who declined participation, signaling the research assistant to not approach those patients. When patients were sitting in a private mammography screening room, a female research assistant introduced herself, and described the purpose of the study. Women were told that their participation was voluntary and confidential. Women were also informed that by consenting, they were also agreeing to be contacted in approximately 18 months via telephone to assess their repeat mammography behavior. The followup telephone contact obtained the following information: (1) whether the participant scheduled an appointment, (2) whether the participant received a reminder letter for the scheduled appointment, and (3) whether the participant obtained a repeat mammogram. If the participant obtained a repeat mammogram, we documented approximately how many months ago the screening was obtained. It should be noted that at the University of Michigan (U-M) breast imaging clinics, there is no systematic reminder system that prompts women to schedule an annual appointment. Instead, only women who schedule appointments receive a reminder letter in the mail and a reminder call two days prior to the patient's mammography appointment.

Interested women provided informed consent and obtained the index mammogram. Following the screening procedure, participants completed a questionnaire (taking $\sim 20 \mathrm{~min}$ ) assessing demographic and health history background, breast cancer knowledge, perceived risk, and screening history, and aspects of the mammography experience. Participants were reimbursed $\$ 10$ for their time and effort.

\section{Dependent variables}

Repeat mammography was defined in two ways: (1) having a mammogram within 12 months of the index mammogram, and (2) having a mammogram within 18 months of the index mammogram. 


\section{Measures}

Demographic background and health history included 11-items assessing age, race/ethnicity, marital status, level of education, employment status, income, health-care coverage, family history of breast cancer, prior breast problems, and prior breast biopsy, and physician recommendation for mammogram at last visit.

Breast cancer knowledge, risk, and screening history included 10 items assessing beliefs about mammography (3 items), lifetime number of mammograms, perceived personal risk of developing breast cancer, relative risk of developing breast cancer, chances of breast cancer being detected at the index screening,

Table I. Mammography experience survey

\begin{tabular}{|c|c|}
\hline Factors and items & Factor loading \\
\hline \multicolumn{2}{|l|}{ Satisfaction with clinic } \\
\hline The mammogram room was pleasant & 0.62 \\
\hline $\begin{array}{l}\text { I was satisfied with how the technologist treated } \\
\text { me }\end{array}$ & 0.68 \\
\hline The waiting room was pleasant & 0.86 \\
\hline $\begin{array}{l}\text { The staff did everything to make me feel } \\
\text { comfortable }\end{array}$ & 0.75 \\
\hline I was satisfied with the care I received & 0.83 \\
\hline $\begin{array}{l}\text { I understand what was going to happen during the } \\
\text { mammogram procedure }\end{array}$ & 0.67 \\
\hline $\begin{array}{l}\text { I was confident the mammogram was performed } \\
\text { properly }\end{array}$ & 0.64 \\
\hline $\begin{array}{l}\text { I was satisfied by how the reception staff treated } \\
\text { me }\end{array}$ & 0.87 \\
\hline $\begin{array}{l}\text { Overall, I was satisfied with my mammogram } \\
\text { experience }\end{array}$ & 0.81 \\
\hline \multicolumn{2}{|l|}{ Physical experience } \\
\hline $\begin{array}{l}\text { The mammogram procedure was painful } \\
\text { The mammogram was physically uncomfortable }\end{array}$ & 0.86 \\
\hline I shall dread having the mammogram again & 0.52 \\
\hline $\begin{array}{l}\text { It was unpleasant to feel my breasts being squeezed } \\
\text { so flat }\end{array}$ & 0.84 \\
\hline Psychological experience & \\
\hline $\begin{array}{l}\text { Having the mammogram made me feel } \\
\text { embarrassed }\end{array}$ & 0.86 \\
\hline Having the mammogram made me feel uneasy & 0.84 \\
\hline $\begin{array}{l}\text { Having the mammogram made me feel awkward } \\
\text { Communication with staff }\end{array}$ & 0.87 \\
\hline I felt free to ask anything and everything & 0.70 \\
\hline $\begin{array}{l}\text { The technologist seemed to be professionally } \\
\text { capable }\end{array}$ & 0.65 \\
\hline $\begin{array}{l}\text { The staff told me all I wanted to know about the } \\
\text { procedure }\end{array}$ & 0.80 \\
\hline $\begin{array}{l}\text { The staff explained what was going to be done to } \\
\text { me during the procedure }\end{array}$ & 0.59 \\
\hline
\end{tabular}

lifetime risk of developing breast cancer, clinical breast exam (CBE) history (in past 5 years), breast self-examination history (in past 6 months), and lifetime number of mammograms.

Mammography experience was assessed using a 20item inventory adapted from an instrument measuring patient satisfaction with mammography developed by Loeken and colleagues [28,29]. Loeken et al.'s [29] original instrument consisted of 27 items and was tested on a population of 550 women attending mammography clinics in Norway. To examine the relevance and applicability of this survey to our population, we administered the survey to a group of radiologists, mammography technologists, and patients obtaining mammography (affiliated with University of Michigan Health System). Based on this pilot, we made several modifications including re-wording some statements (e.g. having a mammogram made me feel embarrassed instead of the examination made me feel embarrassed) and substituting terminology (e.g. technologist instead of examiner), and dropped items that were not relevant to the mammography experience in our population (e.g. the examination was too expensive).

Using the modified instrument, a factor analysis (principal components with oblique rotation) yielded four distinct factors (with eigenvalues greater than 1) accounting for $65 \%$ of the variance. These factors were all correlated with each other (see Table 2) and included satisfaction with clinic (9 items), physical experience (4 items), psychological experience (3 items), and communication with staff (4 items). Responses to items were scored on a 5point Likert scale from 'strongly disagree' $=1$ to 'strongly agree' $=5$. Separate factor scores were calculated by taking the mean of factor item scores. The overall measure had good reliability (Cronbach's alpha $=0.73$ ). Good to excellent reliability was also found for the separate factors of satisfaction with clinic, communication, physical experience, and psychosocial experience (Cronbach's alpha $=0.91,0.82,0.84,0.73$, respectively). Table 1 presents the factors, items, and factor loadings of the Mammography Experience Survey.

\section{Statistical analyses}

Statistical analyses were conducted using the Statistical Package for the Social Sciences software

Table 2. Pearson correlations between MES factor scales $(n=397)$

\begin{tabular}{lccc}
\hline & $\begin{array}{c}\text { Satisfaction } \\
\text { with clinic }\end{array}$ & $\begin{array}{c}\text { Physical } \\
\text { experience }\end{array}$ & $\begin{array}{c}\text { Psychological } \\
\text { experience }\end{array}$ \\
\hline Satisfaction with clinic service & $\mid$ & 1 & \\
Physical experience & $-0.191^{\dagger}$ & $0.373^{\dagger}$ & $\mid$ \\
Psychological experience & $-0.258^{\dagger}$ & $-0.146^{\dagger}$ & $-0.243^{\dagger}$ \\
Communication with staff & $0.635^{\dagger}$ & $\mid$ \\
\hline
\end{tabular}

${ }^{\dagger} p<0.01$. 
13.0 for Mac OS X. Descriptive analyses were conducted for demographic background and health history, breast cancer knowledge, risk, and screening history, and mammography experience.

A series of logistic regression models were conducted separately predicting repeat mammography at 12 and 18 months. The first model examined the demographic and health history variables as independent variables. The second model examined the breast cancer knowledge, risk, and screening history as independent variables. The third model examined the components of the mammography experience as well as whether a woman scheduled a repeat mammography appointment as independent variables. We excluded 'having received a reminder letter' as a variable in the third model due to the high colinearity with 'whether a woman scheduled a repeat mammography appointment'. Reminder letters were only sent to women who have scheduled an appointment. Variables with a significance level of $p<0.05$ were considered as significant predictors of repeat mammography.

Significant predictors from the three separate models were then entered into a final model to identify the best predictors of repeat mammography behavior at 12 and 18 months. An odds ratio of 1 or greater with $95 \%$ confidence intervals and two-tailed $p<0.05$ indicated a significant relationship between the independent variable and repeat mammography.

\section{Results}

Of the 397 women obtaining an index mammogram, we were able to contact 296 women at the 18 -month follow-up yielding a response rate of $75 \%$. Among the women who did not participate in the repeat mammography phase of the study, major reasons included: unable to be reached after three phone calls $(n=57)$, deceased $(n=1)$, telephone was disconnected $(n=22)$, and no longer at the contact number provided $(n=21)$. Results are based on these 296 women. Table 3 presents the demographic and health history information. Fifty-six percent $(n=167)$ were 50 years and older; $88 \%(n=261)$ identified as white; $77 \%(n=227)$ were currently married; $56 \%(n=165)$ had a college education or greater; $61 \%(n=175)$ had an income of $\$ 60000$ or more; $57 \%(n=170)$ were currently working; and 94\% $(n=278)$ reported having health-care coverage. Twenty-one percent $(n=60)$ of women reported a family history of breast cancer; $21 \%$ $(n=63)$ have had prior breast problems; and 16\% $(n=48)$ had a prior breast biopsy.

Table 4 presents the breast cancer knowledge, risk, and screening history. On average, women reported having nine mammograms over their lifetime. While a majority $(93 \%)$ of women
Table 3. Demographic and health history for women contacted at follow-up $(n=296)$

\begin{tabular}{|c|c|c|c|}
\hline Variables & Total $\mathbf{N}$ & $n$ & $\%$ \\
\hline Age & 296 & & \\
\hline 40-49 years & & 129 & 44 \\
\hline 50-64 years & & 120 & 40 \\
\hline 65 or more years & & 47 & 16 \\
\hline Race & 296 & & \\
\hline Minority & & 35 & 12 \\
\hline White & & 261 & 88 \\
\hline Marital status & 295 & & \\
\hline Not married & & 68 & 23 \\
\hline Currently married & & 227 & 77 \\
\hline Education & 296 & & \\
\hline High school or less & & 51 & 17 \\
\hline Partial college & & 80 & 27 \\
\hline College grad or more & & 165 & 56 \\
\hline Income & 284 & & \\
\hline Less than $\$ 19000$ & & 19 & 7 \\
\hline 20000-39999 & & 39 & 14 \\
\hline $40000-59999$ & & 51 & 18 \\
\hline 60000 or more & & 175 & 61 \\
\hline Employment & 296 & & \\
\hline Not working & & 126 & 43 \\
\hline Currently working & & 170 & 57 \\
\hline Insurance & 296 & & \\
\hline No & & 16 & 5 \\
\hline Yes & & 278 & 94 \\
\hline Don't know & & 2 & । \\
\hline Family history of breast cancer & 293 & & \\
\hline No & & 233 & 79 \\
\hline Yes & & 60 & 21 \\
\hline Had prior breast problems & 295 & & \\
\hline No & & 232 & 79 \\
\hline Yes & & 63 & 21 \\
\hline Had prior breast biopsy & 296 & & \\
\hline No & & 248 & 84 \\
\hline Yes & & 48 & 16 \\
\hline Doctor recommended mammogram & 290 & & \\
\hline No & & 30 & 10 \\
\hline Yes & & 260 & 90 \\
\hline
\end{tabular}

believed that they have the same or less risk of developing breast cancer as women of similar age and family history, approximately one-fifth of women believed there was a $30 \%$ or greater chance that their index mammogram would detect breast cancer that day. Eighty percent have had three or more CBEs in the past 5 years, and $57 \%$ had performed three or more breast self-exams in the past 6 months.

\section{Components of the mammography experience}

On a scale of 1-5 with higher scores indicating stronger agreement, mean ratings for satisfaction with clinic service and communication with staff were relatively high (i.e. indicating greater satisfaction) at $4.52(\mathrm{SD}=0.51)$, and $4.50(\mathrm{SD}=0.59)$, respectively. Mean rating for psychological experience was relatively low (less psychological distress) at $1.90(\mathrm{SD}=0.92)$, while mean rating for physical experience was moderate at $2.71(\mathrm{SD}=0.89)$. 
Table 4. Breast cancer knowledge, risk, and screening history

\begin{tabular}{|c|c|c|c|}
\hline Variables & Total $\mathbf{N}$ & Mean & SD \\
\hline $\begin{array}{l}\text { Mammograms can detect all breast } \\
\text { cancers even if they are extremely } \\
\text { small }{ }^{\mathrm{a}}\end{array}$ & 294 & 2.32 & 1.12 \\
\hline $\begin{array}{l}\text { If I have a mammogram, I do not need } \\
\text { to have a clinical breast exam }{ }^{\text {a }}\end{array}$ & 296 & 1.53 & 0.70 \\
\hline $\begin{array}{l}\text { If I have a mammogram, I do not need } \\
\text { to perform monthly breast self-exam- } \\
\text { inations }{ }^{\mathrm{a}}\end{array}$ & 296 & 1.52 & 0.71 \\
\hline Number of mammograms in lifetime & 288 & 8.82 & 6.74 \\
\hline $\begin{array}{l}\text { Personal risk of breast cancer } \\
(0-100 \%)\end{array}$ & 275 & 26.79 & 20.51 \\
\hline \multirow{2}{*}{$\begin{array}{l}\text { Lifetime risk for risk of breast cancer } \\
(0-100 \%)\end{array}$} & 274 & 32.24 & $|8.9|$ \\
\hline & & $\mathbf{N}$ & $\%$ \\
\hline $\begin{array}{l}\text { Risk of breast cancer compared with } \\
\text { other women }\end{array}$ & 290 & & \\
\hline Less & & 91 & 31 \\
\hline Same & & 180 & 62 \\
\hline More & & 19 & 7 \\
\hline $\begin{array}{l}\text { Odds mammogram will detect breast } \\
\text { cancer today }\end{array}$ & 295 & & \\
\hline Less than $1 \%$ & & 154 & 52 \\
\hline $5-20 \%$ chance & & 83 & 28 \\
\hline $30 \%$ chance or greater & & 58 & 20 \\
\hline $\begin{array}{l}\text { How many clinical breast exams in the } \\
\text { past } 5 \text { years }\end{array}$ & 296 & & \\
\hline $0-2$ exams & & 59 & 20 \\
\hline 3 exams or more & & 237 & 80 \\
\hline $\begin{array}{l}\text { Number of breast self-examinations in } \\
\text { the past } 6 \text { months }\end{array}$ & 296 & & \\
\hline $0-2$ exams & & 127 & 43 \\
\hline 3-4 exams & & 93 & 31 \\
\hline 5 or more exams & & 76 & 26 \\
\hline
\end{tabular}

a'Scored on a 5-point Likert scale from "I" = strongly disagree to " 5 " = strongly agree.

\section{Rates of repeat mammography at 12 and 18 months}

Thirty-seven percent $(N=109)$ of women reported having obtained a repeat mammogram within 12 months of the index mammogram, while $68 \%$ $(n=200)$ reported having obtained a repeat mammogram within 18 months.

\section{Predictors of repeat mammography at 12 months}

No significant predictors were found for the demographics and health history model. The breast cancer knowledge, risk, and screening model were significant $\left(\chi^{2}=32.80, p=0.002\right)$ with frequency of CBEs $(B=0.826, \quad p=0.040)$, perceived mammography efficacy $(B=0.300, p=0.31)$, and lifetime number of mammograms $(B=0.092, p<0.001)$ as predictors of repeat mammography at 12 months. Specifically, women who had obtained three or more CBEs in the past 5 years, did not believe that mammograms could detect all breast cancers, and had a greater number of mammograms over the lifetime were more likely to have obtained a repeat mammogram within 12 months of the index mammogram.
The mammography experience model was significant $\left(\chi^{2}=99.97, \quad p<0.001\right)$ with satisfaction with clinic services $(B=-1.143, p<0.012)$ as the only predictor for 12 -month repeat mammography. Women who were less satisfied with the clinic services were more likely to obtain a repeat mammogram at 12 months.

\section{Final model: 12 months}

The significant predictors found from the previous three models were entered into the final model predicting repeat mammography at 12 months (see Table 5). The final model was significant $\left(\chi^{2}=28.08, \quad p<0.001\right)$ with frequency of CBEs $(B=0.848, p=0.023)$ and lifetime number of mammograms $(B=0.074, p<0.001)$ emerging as significant predictors of repeat mammography at 12 months. Specifically, women who have had three or more CBEs in the past 5 years and obtained a greater number of mammograms over their life were 2.33 times and 1.08 times, respectively, more likely to have obtained a mammogram at 12 months.

\section{Repeat mammography at 18 months}

No significant factors were found for the demographic and health history model. The breast cancer knowledge, risk, and screening history model were significant $\left(\chi^{2}=33.65, p<0.001\right)$ with number of lifetime mammograms $(B=0.112, p<0.001)$ and odds the index mammogram will detect breast cancer $(B=0.80, p=0.047)$ as predictors of repeat mammography at 18 months. Women who had a greater number of lifetime mammograms and believed there was less than $1 \%$ chance that the index mammogram was going to detect cancer (compared with women who believed there was a $30 \%$ chance or greater) were more likely to have had a repeat mammogram at 18 months.

The mammography experience model was significant $\left(\chi^{2}=75.32, p<0.001\right)$ with scheduling a mammography appointment $(B=2.50, p<0.001)$ as the only significant predictor of repeat mammography at 18 months. Women who scheduled a mammography appointment were more likely to have had a repeat mammogram than women who did not schedule an appointment.

\section{Final model: 18 months}

Significant predictors from the three separate models were included in the final model predicting repeat mammography at 18 months (see Table 5). The final model was significant $\left(\chi^{2}=84.57\right.$, $p<0.001)$ with number of lifetime mammograms $(B=0.083, p=0.002)$, and scheduling a mammogram appointment $(B=2.475, p<0.001)$ as significant predictors for repeat mammography at 18 months. Women who had a greater number of 
Table 5. Final models predicting repeat mammography at 12 and 18 months

\begin{tabular}{|c|c|c|c|c|}
\hline & $\chi$ & B & OR & $95 \% \mathrm{Cl}$ \\
\hline \multicolumn{5}{|l|}{12 months } \\
\hline Final model & $28.08^{\ddagger}$ & & & \\
\hline$\sharp$ clinical breast exams in past 5 years & & $0.848^{*}$ & 2.33 & I.12, 4.85 \\
\hline Mammograms can detect all breast cancer $^{\mathrm{a}}$ & & 0.230 & 1.26 & $0.99,1.60$ \\
\hline Lifetime number of mammograms & & $0.076^{\ddagger}$ & 1.08 & $1.04,1.12$ \\
\hline Satisfaction with clinic & & -0.406 & 0.67 & $0.40,1.12$ \\
\hline \multicolumn{5}{|l|}{18 months } \\
\hline Final model & $84.57^{\ddagger}$ & & & \\
\hline Lifetime number of mammograms & & $0.083^{\ddagger}$ & 1.09 & $1.03,1.14$ \\
\hline Scheduled a repeat mammography appointment & & $2.475^{\ddagger}$ & 11.88 & $6.26,22.56$ \\
\hline \multicolumn{5}{|l|}{ Odds mammogram will detect cancer today } \\
\hline Less than $1 \%$ chance & & 0.526 & 1.69 & $0.76,3.76$ \\
\hline $5-20 \%$ chance & & 0.178 & 1.20 & $0.50,2.84$ \\
\hline $30 \%$ or greater chance & & Reference & & \\
\hline
\end{tabular}

${ }^{*} p<0.05,{ }^{\dagger} p<0.01,{ }^{\dagger} p<0.001$.

${ }^{a}$ Variable was reverse coded.

lifetime mammograms and scheduled a mammography appointment were 1.09 times and 11.88 times more likely to obtain a repeat mammogram within 18 months.

\section{Discussion}

The purpose of this study was to explore the different aspects that contribute to women's mammography experience, to examine the rates of repeat mammography behavior, and to identify the significant predictors of repeat mammography among women obtaining a screening mammogram at university-affiliated breast imaging clinics.

To assess mammography experience, we modified an instrument originally developed by Loeken and colleagues $[28,29]$ using a population in Norway. In contrast to Loeken et al.'s survey [29], our instrument included fewer items (20 versus 27), fewer factors (4 versus 8), and accounted for a greater amount of variance (65 versus 57\%) associated with women's experience with mammography. Loeken et al.'s [29] factor analysis yielded eight factors including physical discomfort, psychological discomfort, waiting time, staff's technical skills, information transfer, future satisfaction, and current satisfaction. Alternatively, using a clinic-based sample in the US, our modified survey identified four major factors including satisfaction with clinic services, physical experience, psychological experience, and communication with the clinic staff. A confirmatory factor analysis should be performed to test this factor structure for other populations of screening-aged women in the US (e.g. community-based clinics, Medicare beneficiaries, medically underserved communities).

Aside from the component of physical discomfort, scores for the other mammography experience components were not symmetrically distributed. In fact, women's satisfaction with clinic service and communication with staff were positively skewed (high ratings), while psychological distress was negatively skewed (low ratings). These asymmetric distributions are not surprising given the high number of average lifetime mammograms $(n=9)$ as well as the low percentage of first-time screeners $(6 \%)$ in our sample. Future studies should oversample for first-time screeners to examine how their mammography experience and repeat mammography behavior differs from more veteran screeners. To capture greater variability, such investigations should also recruit more racially, culturally, economically, and geographically diverse patients from different health-care systems.

This study reported a repeat mammography rate of $37 \%$ at 12 months and $68 \%$ at 18 months. Our 12 -month rate is lower than the 12-month rate $(49 \%)$ found in a large representative sample of women aged 55-79 participating in the Year 2000 National Health Interview Survey [30]. Our 18month repeat mammography rate is similar to the $67 \%$ rate found among a sample of 23011 Medicare beneficiaries, aged 40 and older (attending imaging facilities with no reminder system) in New York State [12]. Both our 12-month and 18month rates fell into the range of $28-92 \%$ reported in Clark et al.'s [14] meta-analysis of repeat mammography studies published between 1995 and 2001.

Our hypothesis that components of women's mammography experience would have the greatest impact on repeat mammography behavior was not supported. While satisfaction with clinic services predicted 12-month repeat screening in a preliminary model, when considered with other factors in the final model, its significance diminished completely. Interestingly, as an initial predictor, satisfaction with clinic services was negatively correlated with repeat mammography. To understand this finding, we need to examine the distribution of the variable. Satisfaction with clinic 
service was scored on a 5-point likert scale with higher scores reflecting greater satisfaction. The mean rating for satisfaction with clinic service was $4.52 \quad(\mathrm{SD}=0.51) \quad$ with approximately $92 \%$ of women 'agreeing' to 'strongly agreeing' that they feel satisfied with clinic services. Therefore among satisfied women, those at the lower end (satisfied) were more likely to obtain repeat mammography than women at the higher end (very satisfied). Given this ceiling effect, it is difficult to arrive at a meaningful interpretation.

Similar to Bobo et al. [11], we found a positive relationship between number of previous mammograms and repeat mammography. This finding held for both 12-month and 18-month screening intervals. It is possible that each new mammography experience reinforces the development of a lifelong screening habit. For this reason, a woman's experience with her first-ever mammogram may be the most critical screening experience in establishing a consistent pattern. Future research on the mammography experience of first-time screeners and its impact on future screening adherence is needed.

Frequency of CBEs emerged as a significant predictor for repeat mammography at 12 months, but not at 18 months. Women who interpret the recommended screening guidelines for mammography as a strict definition (i.e. annual mammogram means obtaining a mammogram every 12 months) likely apply this to other screening modalities such as $\mathrm{CBE}$. Based on this reasoning, it is not surprising that women who obtain CBEs at the recommended frequency are more likely to obtain annual mammography within 12 months rather than 18 months, which would be considered 'late'.

Results found that women who scheduled a mammography appointment were 11.32 times more likely to obtain repeat screening at 18 months. The act of scheduling an appointment not only strengthens one's personal commitment, but also, in some health-care systems (e.g. UMHS), it cues the clinic to send some form of a reminder. A limitation to this type of system is that it completely relies on the patient to be proactive in scheduling annual mammograms. Patients with less initiative in obtaining regular screening may require a different approach. For instance, a clinic-based intervention could instruct staff to schedule all patients' annual mammograms at the time of their current screening visit. This simple protocol would ensure that every woman receive a reminder communication (e.g. letter, postcard, automated telephone call), yet would incur minimal administrative cost.

Alternatively, clinics can implement a formal reminder system that prompts patients to schedule their annual mammogram two months prior to their next recommended screening date. Several studies have demonstrated the efficacy of reminder systems in increasing rates of repeat mammography $[31,32]$. According to a study by Rakowski et al. [32] a simple, low-cost reminder system (e.g. mailing a letter) is equally effective as resourceintensive, patient-tailored reminder methods.

There were several limitations to the present study. A majority of our sample identified as Caucasian, had a college degree, and had healthcare coverage. These demographic and health-care characteristics have all been positively associated with obtaining a repeat mammography in past research. Given the demographic and socioeconomic homogeneity of our sample, our results cannot be generalized to the larger population. However, without the influence of these factors, we were able to identify a screening barrier (e.g. lack of appointment scheduling) that can be addressed.

Our study was also limited by an attrition rate of $25 \%$ from the index mammogram recruitment to the repeat mammogram follow-up. Among the 397 women recruited for the index mammogram, only 296 women could be reached to determine the status of repeat mammography. It is likely this attrition rate is, in part, due to the transitory nature of a University community. In fact, $43 \%(n=43)$ of the women lost to follow-up had their telephone disconnected or had moved from the area. It is certainly possible that these women obtained repeat mammography at their new location. Given this elevated attrition rate, retention efforts for future similar studies may require a multi-pronged approach such as a combination of clinic records review, health insurance claims, and self-report. Furthermore, when enrolling participants into a longitudinal study with follow-up at 18 months (or longer), the informed consent protocol should require participants to provide names of two people that would be knowledgeable of any change in residence or contact information.

The optimal benefit of mammography in reducing breast cancer-related mortality relies on consecutive on-schedule screening over the lifetime. While our study population of experienced screeners did not provide the variability needed to adequately examine the impact of women's mammography experience on repeat mammography, this question remains important particularly among first-time screeners. However, among this group of veteran screeners with few demographic risk factors, the behavior of scheduling an annual mammogram is clearly a significant facilitator for screening adherence. Future investigations should compare the feasibility and cost of different clinic-based approaches (reminder system versus on-site scheduling) with improved long-term screening adherence.

\section{Acknowledgements}

This study was supported by the William N. Hubbard, Jr, Endowed Fellowship whose mission is to improve the 
quality of clinical care through the collaboration of professionals in diverse health disciplines. We also thank Jill Chokshi, Jenel Wyatt, and Suma Amarnath, who assisted with participant recruitment during their undergraduate and medical training years.

\section{References}

1. Jemal A, Siegel R, Ward E, Murray T, Xu J, Thun MJ. Cancer statistics, 2007. CA Cancer J Clin 2007;57:43-66.

2. Michigan Public Health Institute (in support of the Michigan Cancer Consortium Initiative). The Cancer Burden in Michigan: Selected Statistics. Okemos, MI, December 2006. Available at: www.michigancancer.org/ PDFs/MCCReports/CancerBurden-Dec2006/CancerBurdenInMichigan-Dec06-AllSections.pdf. Accessed on: November 20, 2007.

3. Duffy SW, Tabar L, Chen $\mathrm{H}$ et al. The impact of organized mammography service screening on breast carcinoma mortality in seven Swedish Counties. Cancer 2002;95:458-469.

4. Tabar L, Yen M, Vitak B, Chen HT, Smith RA, Duffy S. Mammography service screening and mortality in breast cancer patients: 20-year follow-up before and after introduction of screening. Lancet 2003;361: 1405-1410.

5. Breast Screening Frequency Trial Group. The frequency of breast cancer screening: results from the UKCCCR randomized trial. United Kingdom Coordinating Committee on Cancer Research. Eur J Cancer 2002;38: 1458-1464.

6. Smith RA, Saslow D, Sawyer KA et al. American Cancer Society guidelines for breast cancer screening: update 2003. CA Cancer J Clin 2003;53:138-140.

7. Breen N, Wagener DK, Brown ML et al. Progress in cancer screening over a decade: results of cancer screening from the 1987, 1992, and 1998 National Health Interview Surveys. J Natl Cancer Inst 2001;93: $1676-1677$

8. National Center for Health Statistics: Health, United States, 2002: With Chartbook on Trends in the Health of Americans. Government Printing Office: Washington, DC, 017-022-01531, 2002.

9. Blackman DK, Bennett EM, Miller DS. Trends in selfreported use of mammograms (1989-1997) and Papanicolaou tests (1991-1997) - behavioral risk factor surveillance system. MMWR 1999;48:1-22.

10. Engelman KK, Ellerbeck EF, Mayo MS, Markello SJ, Ahluvalia JS. Mammography facility characteristics and repeat mammography use among Medicare beneficiaries. Prev Med 2004;39:491-497.

11. Bobo JK, Shapiro JA, Schulman J, Wolters CL. Onschedule mammography rescreening in the National Breast and Cervical Cancer Early Detection Program. Cancer Epidemiol Biomarkers Prev 2004;13:620-630.

12. Quinley J, Mahotiere T, Messina CR, Lee T, Mikail C. Mammography-facility-based patient reminders and repeat mammograms for Medicare in New York State. Prev Med 2004;38:20-27.

13. Barr J, Franks A, Lee N, Herther F, Schachter M. Factors associated with continued participation in mammography screening. Prev Med 2001;33:661-667.

14. Clark MA, Rakowski W, Bonacore LB. Repeat mammography: prevalence estimates and considerations for assessment. Ann Behav Med 2003;26:201-211.

15. Phillips KA, Kerlikowske K, Baker LC, Chang SW, Brown ML. Factors associated with women's adherence to mammography screening guidelines. Health Serv Res 1998;33:29-53.

16. Yood MU, McCarthy BD, Lee NC, Jacobsen G, Johnson CC. Patterns and characteristics of repeat mammography among women 50 years and older. Cancer Epidmiol Biomarkers Prev 1999;8:595-599.

17. Calvocoressi L, Kasl SV, Lee CH, Stolar M, Claus EB, Jones BA. A prospective study of perceived susceptibility to breast cancer and nonadherence to mammography screening guidelines in African American and White Women Ages 40-79. Cancer Epidemiol Biomarkers Prev 2004;13:2096-2105.

18. Gross CP, Filardo G, Singh HS, Freedman AN, Farrell $\mathrm{MH}$. The relation between projected breast cancer risk, perceived cancer risk, and mammography use. Results from the National Health Interview Survey. J Gen Intern Med 2006;21:158-164.

19. Elwood M, McNoe B, Smith T, Bandaranayake M, Doyle T. Once is enough - why some women do not continue to participate in a breast cancer screening programme. N Z Med J 1998;111:180-183.

20. Drossaert CHC, Boer H, Seydel ER. Does mammographic screening and a negative result affect attitudes towards future screening? J Med Screen 2001;8:204-209.

21. Kashikar-Zuck S, Keefe FJ, Kornguth P, Beaupre P, Holzberg A, Delong D. Pain coping and the pain experience during mamography: a preliminary study. Pain 1997;73:165-172.

22. Keefe FJ, Hauck ER, Egert J, Rimer B, Kornguth P. Mammography pain and discomfort: a cognitivebehavioral perspective. Pain 1994;56:247-260.

23. Kornguth PJ, Keefe FJ, Conaway MR. Pain during mammography: characteristics and relationship to demographic and medical variables. Pain 1996;66: 187-194.

24. Marshall G. A comparative study of re-attenders and non-re-attenders for second triennial National Breast Screening Programme appointments. J Public Health Med (Oxf) 1994;16:79-86.

25. Orton M, Fitzpatrick R, Fuller A, Mant D, Mlynek C, Thorogood M. Factors affecting women's response to an invitation to attend for a seond breast cancer screening examination. Br J Gen Pract 1991;41:320-323.

26. Peipins LA, Shapiro JA, Bobo JK, Berkowitz Z. Impact of women's experiences during mammography on adherence to rescreening (United States). Cancer Causes Control 2006;17:439-447.

27. Somkin CP, McPhee SJ, Nguyen T et al. The effect of access and satisfaction on regular mammogram and Papanicolaou test screening in a multiethnic population. Med Care 2004;42:914-926.

28. Loeken K, Steine S, Sandvik L, Laerum, E. A new instrument to measure patient satisfaction with mammography: validity, reliability, and discriminatory power. Med Care 1997;35:731-741.

29. Loeken K, Steine S, Sandvik L, Laerum E, Finset A. A new measure of patient satisfaction with mammography. Validation by factor analytic technique. Fam Pract 1996;13:67-74.

30. Rakowski W, Breen N, Meissner H et al. Prevalence and correlates of repeat mammography among women aged 55-79 in the Year 2000 National Health Interview Survey. Prev Med 2004;39:1-10.

31. Mayer JA, Lewis EC, Slymen DJ et al. Patient reminder letters to promote annual mammograms: a randomized controlled trial. Prev Med 2000;31:315-322.

32. Rakowski W, Lipkus IM, Clark MA et al. Reminder letter, tailored stepped-care, and self-choice comparison for repeat mammography. Am J Prev Med 2003;25: 308-314. 